\title{
ATRÁS DO PREJUÍZO: O PROJETO DE PAISAGISMO PARA O ENTORNO AO EDIFíCIO BIOMÉDICAS IV, CUASO, SP
}

PAULO RENATO MESQUITA PELLEGRINO 


\section{RESUMO}

Como deve ser um projeto paisagístico em uma situação de degradação já ocorrida do sítio? E, como deve ser a sua inserção dentro de uma realidade como a do campus da USP, em São Paulo? Aqui é apresentado, com este projeto, uma outra possibilidade de papéis para estes espaços livres.

\section{ABSTRACT}

$\mathrm{H}$

ow must be a landscape design for an already degraded area? And, how could be its role for a reality as that of the Campus of São Paulo University, in São Paulo city? The design, here presented, discuss the possibilities in changing the actual conditions. 
No no uso dos espaços livres do campus, de enfrentamento da aparente desconsideração observada pelo tratamento recebido por estes espaços e a conseqüente incapacidade de percepção do seu valor e mesmo de sua existência pelos milhares de usuários que diariamente transitam pelo campus, é que aceitamos o convite formulado pela direção do Instituto de Ciência Biomédicas para a realização do projeto para o entorno do seu novo edifício.

Este projeto de 1994, de autoria dos arquitetos paisagistas Paulo Pellegrino e Catharina Lima, cria uma intervenção na paisagem do campus da USP, em São Paulo, que visa enfatizar o caráter que os seus espaços livres podem desempenhar no contexto das vivências cotidianas e do ambiente urbano. Como uma reação ao processo de desaparecimento virtual destes espaços, com ênfase em sua neutralização através de uma sua transformação previsível em uma realidade pasteurizada, formada de espaços neutros e suavizados, com o correlato empobrecimento das experiências cotidianas que podem proporcionar, este projeto procurou responder à necessidade de definição de novos papéis a serem desempenhados por estes espaços, além de serem meras molduras verdes para os edifícios que compõem o campus da universidade.

Localizado no topo do morro culminante dentro da área do campus, que havia sofrido um trabalho de terraplenagem extensivo, com o objetivo de abrigar em um único platô não só o edifício em si, mas toda a área de circulação e estacionamento prevista, deparamos com uma situação usual em nosso meio, de total desconsideração com o perfil topográfico original, com a perda do solo superficial e da vegetação existente, com a exposição de um substrato frágil e estéril. 


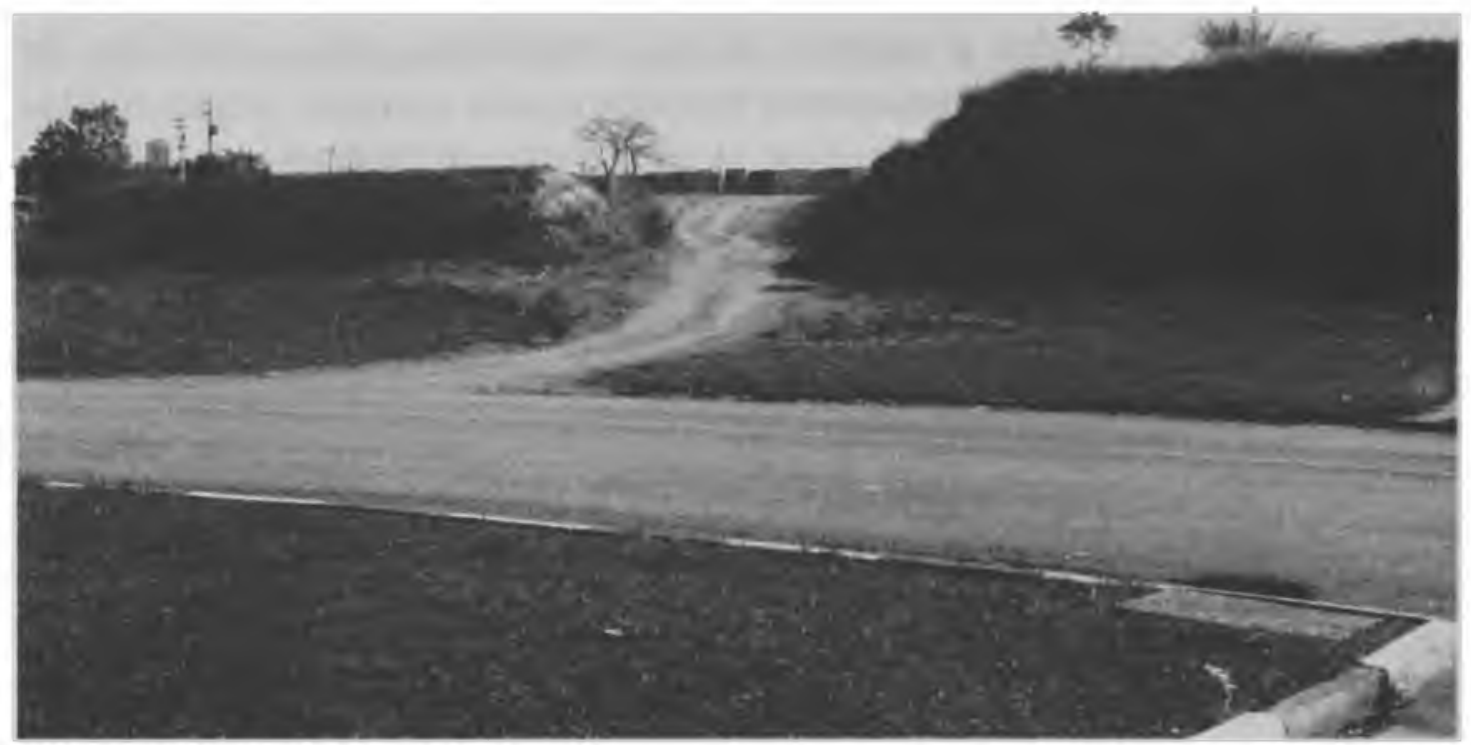

Foto 1- Perfil original do terreno.

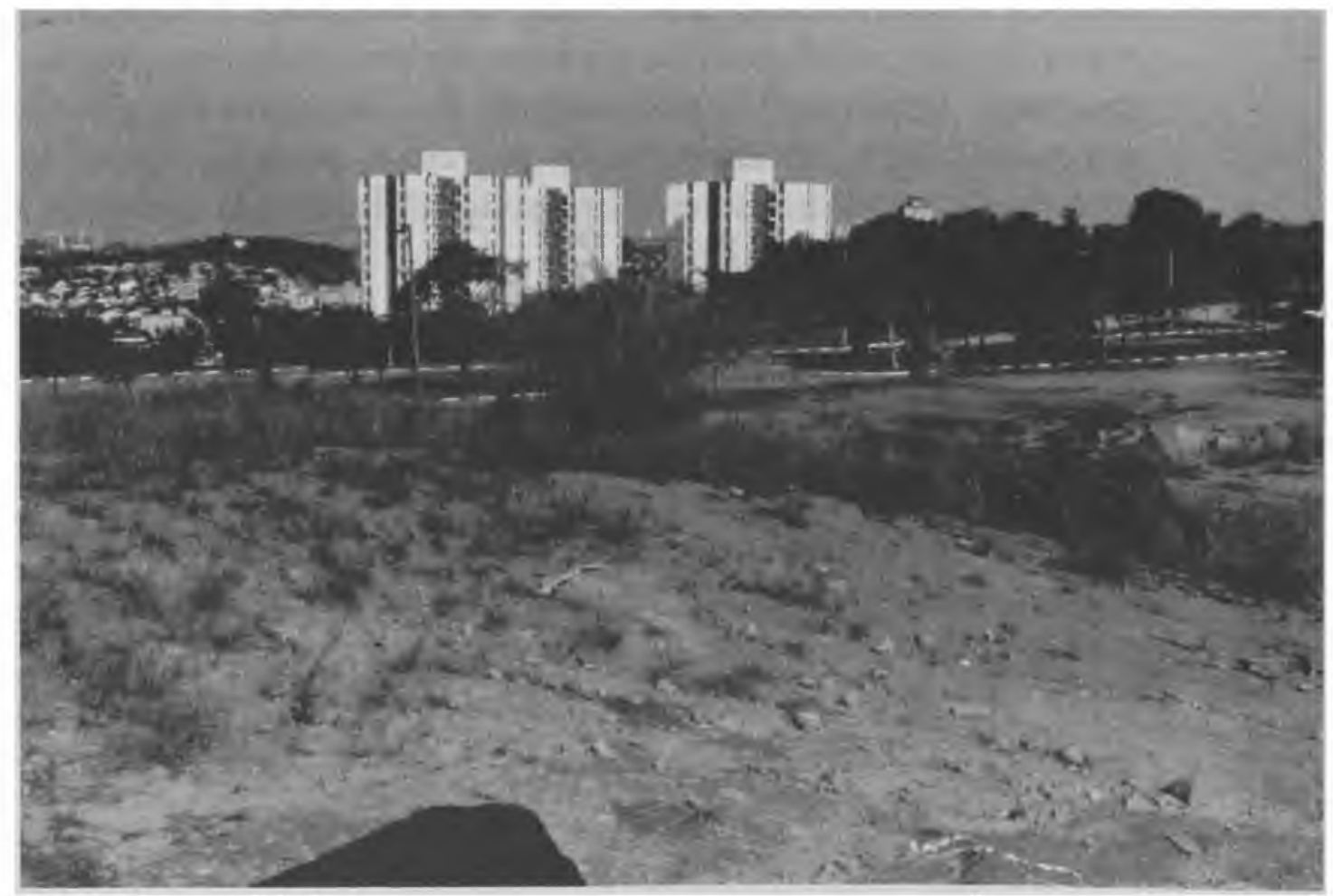

Foto 2- Visão geral da área. 


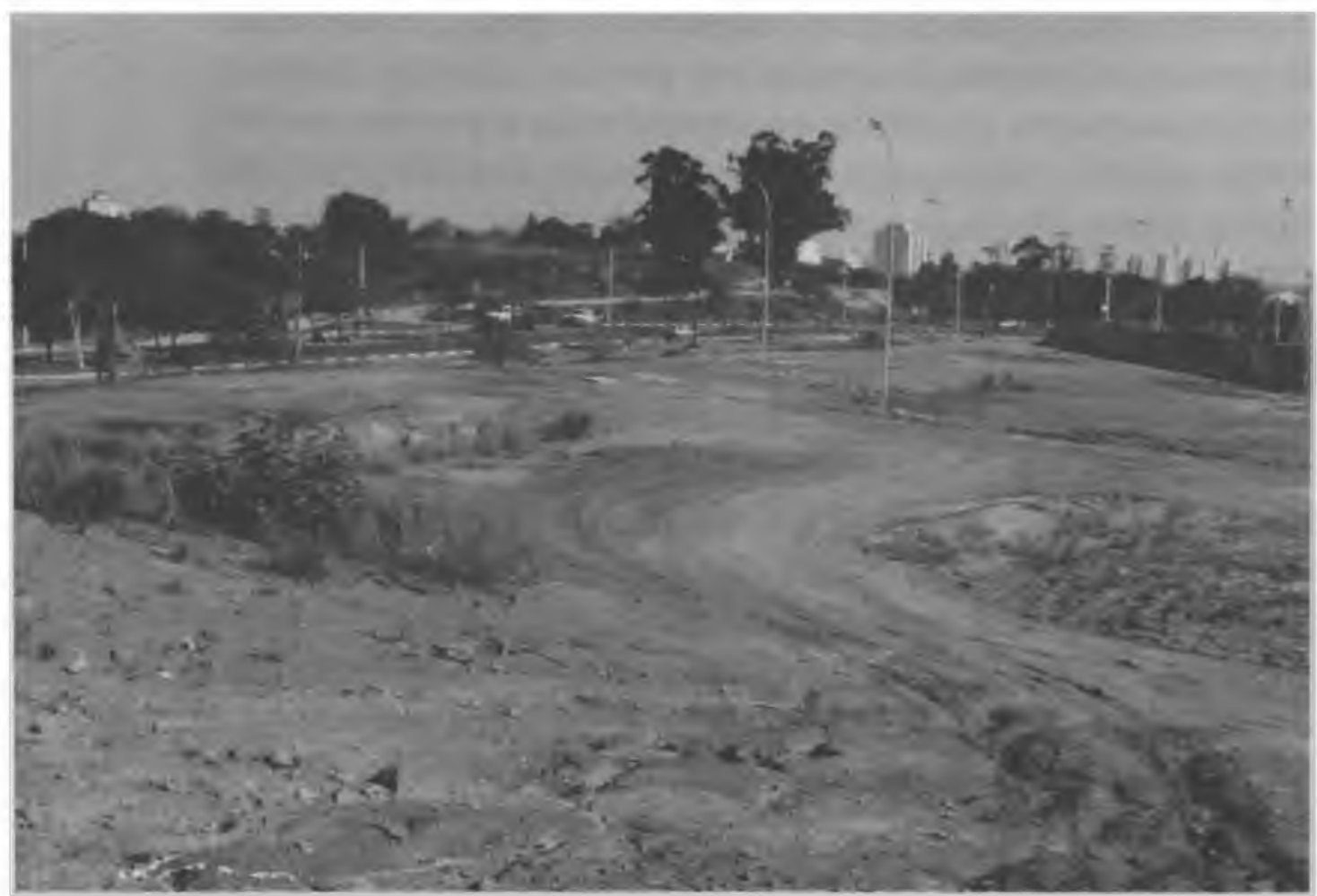

Foto 3 - Extensão do movimento de terras.

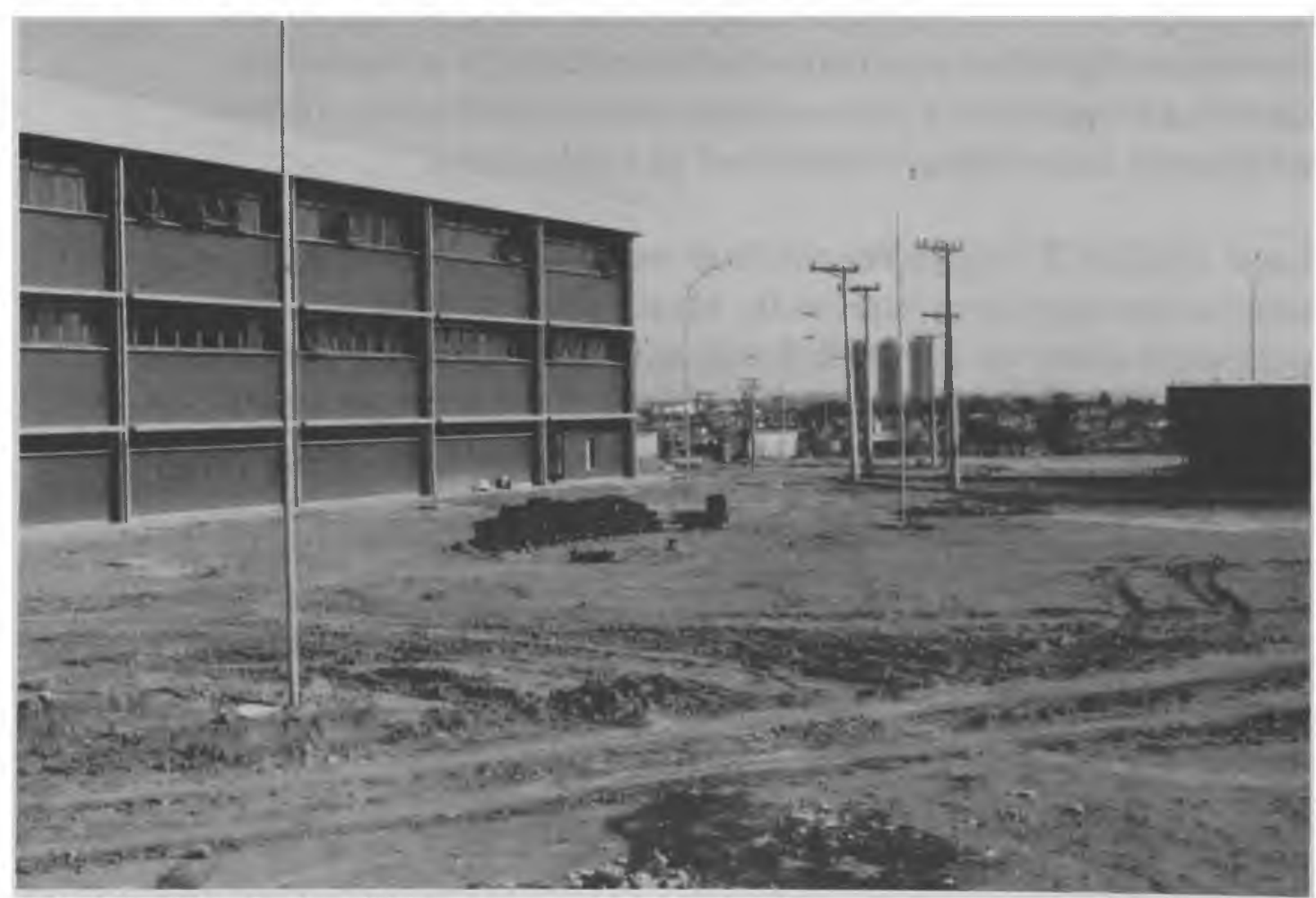

Foto 4 - Implantação dos edifícios. 
Eram previstos, ainda, segundo os planos originais, a existência de uma nova vegetação apenas em exígüos espaços residuais entre uma imensa superfície a ser pavimentada por um revestimento asfáltico contínuo por todo o entorno da edificação, que ficaria, assim, ilhada por uma imensa superfície impermeabilizada, que além de resultar em aspectos de conforto adversos aos seus usuários, viria a comprometer ainda mais um setor de bacia hidrográfica já totalmente comprometido em sua drenagem superficial.

Tendo de assumir estes condicionantes prévios representados por esta situação de alteração do sítio original - inclusive a programação de uma quantidade de vagas de estacionamento que consumiria a quase totalidade da superfície disponível consideramos que este espaço, por suas dimensões evisualização dentro do campus, deveria representar um processo de recuperação de uma área degradada por um movimento de terra indiscriminado, a partir do repovoamento vegetal em seus diversos extratos, com a conquista da maior superfície de percolação possível. Além da criação de uma ambientação que conferisse dignidade a um importante instituto da universidade, banalizado que estava, por um projeto de arquitetura do edifício totalmente burocrático e previsivel já implantado.

Com relação à vegetação adotada no projeto, optamos pela seleção de espécimes nativas de características pioneiras, que pudessem enfrentar as condições de solo, drenagem e insolação existentes, que, num trabalho de sucessão vegetal, propiciassem a recuperação das condições do ambiente local. Na procura pela também desejada compatibilização com os requisitos simbólicos dos usos humanos, esta vegetação também atendeu a soluções formais como esplanadas, colunatas de árvores e maciços escalonados, enfatizando mudanças de níveis, direcionando visuais e criando barreiras. 
Assim, em conjunto com os materiais empregados no revestimento dos caminhos eáreas de estacionamento, como o emprego de blocos vazados, procurou-se alcançar uma compatibilização possivel entre os elementos aparentemente contraditórios de uma visão ecológica purista e os requisitos funcionais e culturais próprios de uma realidade urbana como São Paulo, inclusive com a utilização de espécies exóticas já validadas em sua história.

A implantação, ora em curso, deste projeto revela o início de uma mudança de percepção do papel que os espaços livres podem desempenhar para a real possibilidade de manutenção da habitabilidade de nossas cidades. Demonstra, também, a busca de uma estética que possa expressar os novos requisitos que os espaços livres deverão assumir, de compatibilização entre os múltiplos interesses e funções que a nossa realidade urbana requer, para a conformação de novos patamares de evolução sócioecológicas, mais viáveis e satisfatórias. 


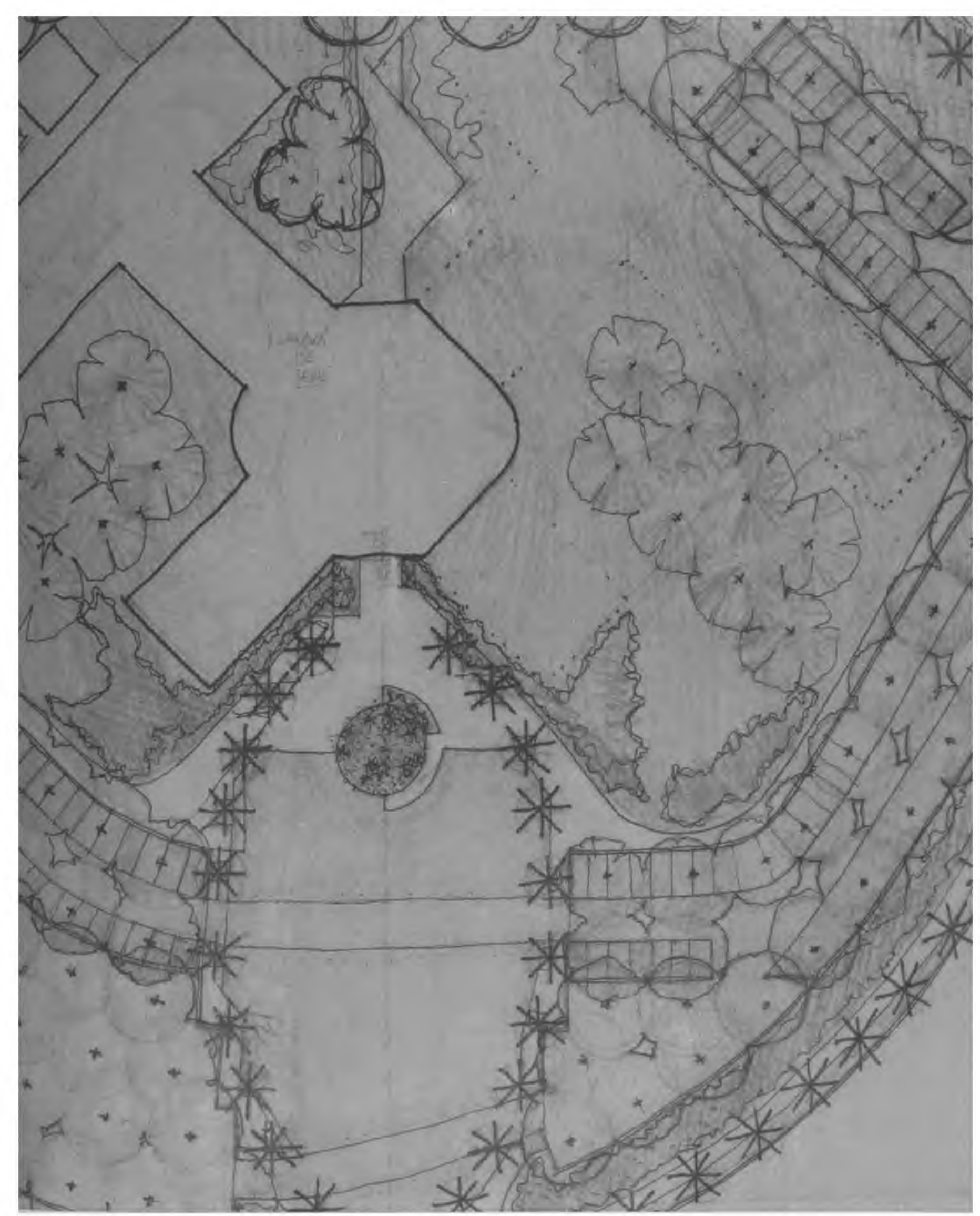

